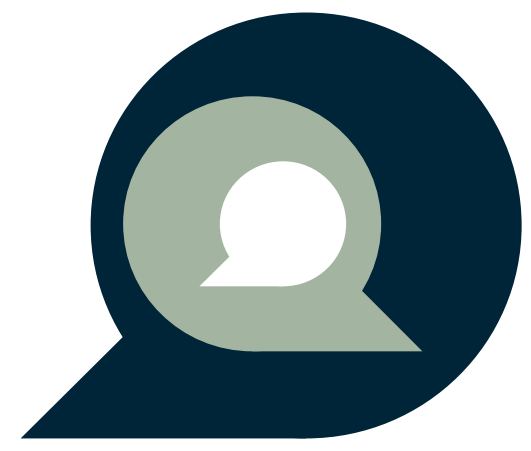




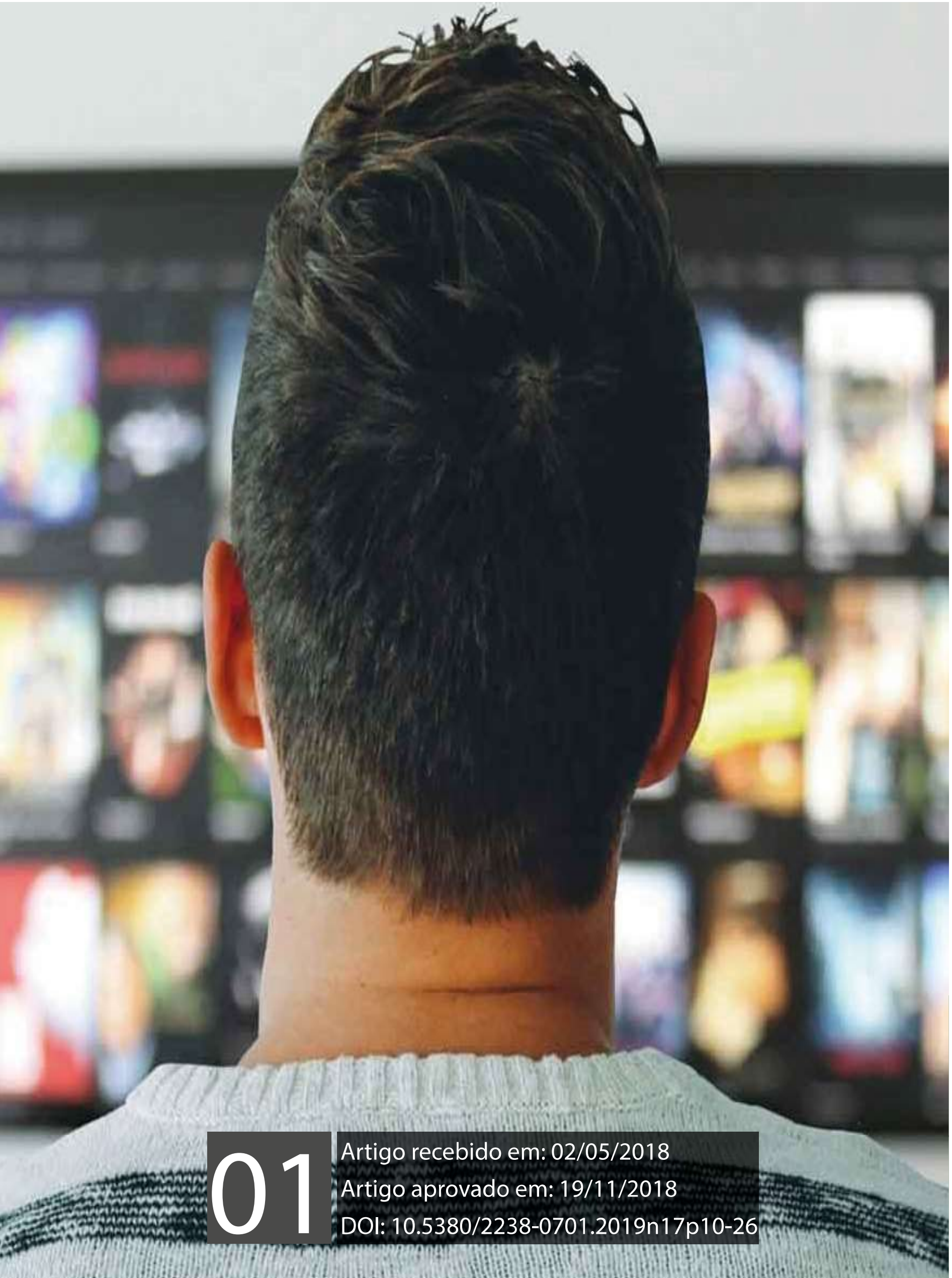

ain

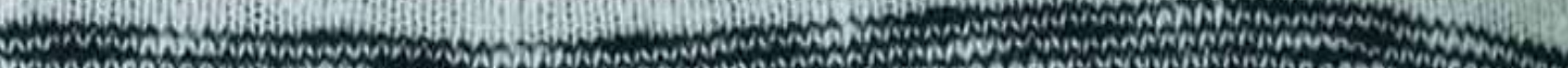
SW

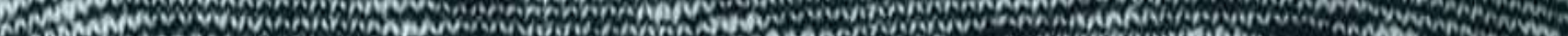

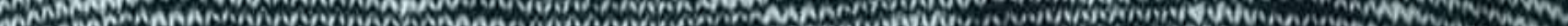

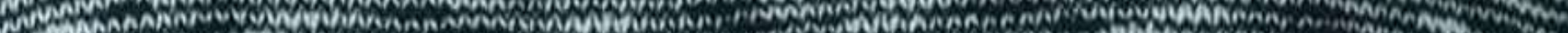

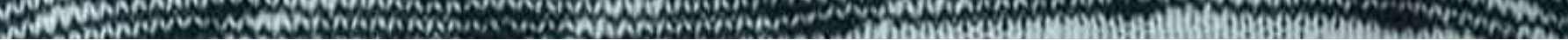


A alimentação na tela da TV: um novo ponto para o biopoder regular nossas vidas? 


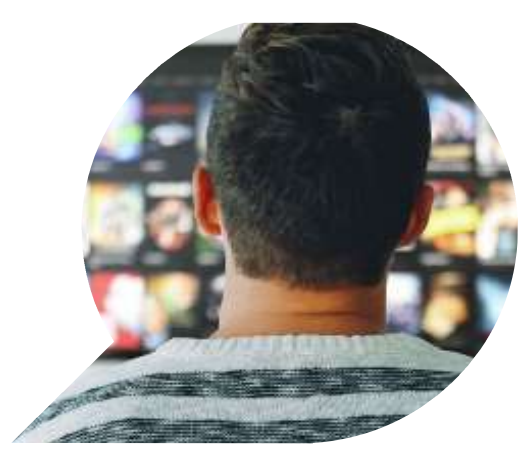

\section{A alimentação na tela da TV: um novo ponto para o biopoder regular nossas vi- das?}

\section{La alimentación en la TV: un nuevo punto para el biopoder regular nuestras vidas?}

\section{The power on the TV screen: a new point for biopower regu- late our lives?}

JEFERSON BERTOLINI ${ }^{1}$

Resumo: Este artigo apresenta resultados de pesquisa sobre o tema alimentação no discurso do programa Bem Estar, da Rede Globo, $e$ no cotidiano do público (entendido aqui como conjunto heterogêneo de indivíduos de uma população). O trabalho usa análise de conteúdo (para apurar o que diz o programa sobre alimentação) e observação participante em supermercado e academia de ginástica (onde as pessoas compram alimentos e exercitam o corpo, respectivamente). O objetivo do texto é analisar o tema alimentação no âmbito do biopoder (técnica de poder que busca produzir corpos economicamente ativos). O artigo conclui que a alimentação, por ser um dado natural (do indivíduo) e universal (da espécie), desponta como novo ponto de intervenção do biopoder sobre a sociedade. Novo porque o sexo

1 Doutor em Ciências Humanas pela Universidade Federal de Santa Catarina. 
já se prestou a isso. A TV, ao tratar do tema alimentação, amplifica este poder de intervenção.

Palavras-chave: Biopoder; Mídia; Alimentação

Resumen: Este artículo presenta resultados de investigación sobre el tema alimentación en el discurso del programa Bienestar, de la Red Globo, y en el cotidiano del público (entendido aquí como conjunto heterogéneo de individuos de una población). El trabajo utiliza análisis de contenido (por determinar lo que dice el programa sobre alimentación) y observación participante en supermercado y gimnasio (donde las personas compran alimentos y ejercitan el cuerpo, respectivamente). El objetivo del texto es pensar el tema de la alimentación en el ámbito del biopoder (técnica de poder que busca producir cuerpos económicamente activos). El artículo concluye que la alimentación, por ser un dato natural (de cada individuo) y universal (de la especie), se desprende como nuevo punto de intervención del biopoder sobre la sociedad. Nuevo porque el sexo ya se prestó a esa intervención. La TV, a tratar el tema alimentación, amplifica esta intervención.

Palabras-clave: Biopoder; Medios de comunicación; Comida

\begin{abstract}
This article presents research results on the topic of food in the discourse of the program Bem Estar, Rede Globo, and in the daily life of the public (understood here as a heterogeneous set of individuals of a population). The work uses content analysis (for clarifying what the program says about food) and participant observation in supermarket and exercise gym (where people buy food and exercise the body, respectively). The purpose of the text is to think about the food theme under the scope of biopower (power technique that seeks to produce economically active bodies). The article concludes that food emerges as a new point of intervention of biopower in society. New because sex has already lent itself to this intervention. TV, addressing the issue of food, amplifies this intervention.
\end{abstract}

Keywords: Biopower; Media; Food 


\section{Introdução}

Este artigo apresenta resultados de pesquisa empírica sobre o tema alimentação no discurso do programa Bem Estar, da Rede Globo, e no cotidiano do público (entendido aqui como conjunto heterogêneo de indivíduos de uma população).

$\mathrm{Na}$ Rede Globo, escolhida por este estudo por ser a maior emissora do Brasil, o tema alimentação ganhou destaque a partir dos anos 2000, com o início de uma série de quadros sobre o corpo apresentados no Fantástico, como viagem ao corpo humano, medida certa e questão de peso. Em 2011, a emissora criou um programa diário para tratar do tema: o Bem Estar, escolhido como objeto de estudo deste trabalho.

Esta pesquisa usa análise de conteúdo do Bem Estar (para apurar o que o programa diz em termos de alimentação) e observação participante com clientes de supermercado e alunos de academia de ginástica (para apurar o que diz o público em termos de alimentação; essas pessoas foram escolhidas como representantes do que aqui chamamos público; supermercado e academia foram escolhidos porque são os locais onde as pessoas compram alimentos e exercitam o corpo, respectivamente).

A proposta deste trabalho não é medir se o discurso do Bem Estar influencia as decisões do público sobre alimentação. Isso seria desnecessário, uma vez que desde 1918 se sabe que os meios de comunicação exercem alguma influência sobre o público (DEFLEUR; BALL-ROKEACH, 1993). A proposta é simplesmente observar no público o mesmo tema observado no programa de TV.

Este artigo pensa a alimentação no âmbito do biopoder (FOUCAULT, 2012). Biopoder é uma técnica de poder que articula disciplina (conjunto de ações que busca adestrar os corpos dos indivíduos) e biopolítica (conjunto de ações que tenta controlar a vida da população como um todo). Significa que, na perspectiva deste trabalho, a alimentação é vista como ponto a partir do qual o biopoder regula as vidas das pessoas.

O texto está dividido em cinco partes. A primeira traz breve literatura sobre a preocupação humana com a alimentação. A segunda apresenta a metodologia do estudo. A terceira destaca o programa Bem Estar. A quarta mostra o que diz o Bem Estar em termos de alimentação. A quinta mostra o que clientes de supermercado e alunos de academia pensam sobre ali- 
mentação.

O artigo conclui que a alimentação, por ser um dado natural (de cada indivíduo) e universal (típico da espécie), desponta como novo ponto de intervenção do biopoder sobre a sociedade. Novo porque, na obra de Foucault (2012), o sexo já desempenhou tal papel.

\section{A preocupação humana com a alimentação}

Na definição de Brothwell (1971, p. 17), alimento "é toda substância sólida ou fluida que permite ao organismo humano desenvolver-se e manter a saúde durante a vida". Sendo assim, um regime alimentar adequado é essencial à população sob dois aspectos: primeiro, um regime deficiente está na origem dos atrasos de crescimento, do mau estado físico e das taxas de mortalidade; segundo, a produção de energia suficiente, sobretudo para manter a capacidade de trabalho em nível ótimo, depende da alimentação.

Ornellas (2000) diz que, da pré-história aos nossos dias, entre as motivações que levam o homem à busca do alimento estão a sobrevivência (fator instintivo, básico e permanente, que tem a fome como impulso normal para a busca do alimento), a saúde (as preocupações com a saúde foram sempre inerentes à própria condição humana, decorrendo principalmente do temor da morte), as dietas (povos de culturas antigas já estabeleciam restrições alimentares em condições especiais, como a gestação), a religião (não estranha que fatores religiosos tenham influído em certos hábitos alimentares, transcendendo a qualquer explicação lógica dentro do raciocínio humano), o aspecto político-social (mesmo os povos mais primitivos reconheceram sempre um soberano, um líder, um chefe, que convertiam, muitas vezes, em divindades, atribuindo-lhes poderes ou honras de verdadeiros deuses), a longevidade (a terra pode não ser um paraíso, mas nem por isso o homem abriu mão de suas pretensões de prolongar indefinidamente a vida), as carências (medo dos flagelos da fome que assolaram a humanidade, principalmente na Idade Média), as ciências (os conhecimentos da nutrição progridem a partir da química, primeiramente em Lavoisier), a tecnologia (com o aprimoramento tecnológico, foram lançadas no mercado farinhas cada vez mais refinadas e se multipli- 
caram as variedades de produtos delas derivados) e a cultura. "O gosto pelos alimentos não é natural; é aprendido" (ORNELLAS, 2000, p. 274).

A alimentação é fonte histórica de preocupação porque o que comemos se converte em nós mesmos. "O vestido e os cosméticos só estão em contato com nosso corpo. Os alimentos devem transpassar a barreira oral, introduzir-se em nós e converter-se em nossa substância íntima" (FISCHLER, 1995, p. 11).

Ao longo da história, nota-se uma permanente preocupação com a alimentação. Isso se dá porque a alimentação é, após a respiração e a ingestão de água, a mais básica das necessidades humanas. "Além de necessidade biológica, a alimentação é um complexo sistema simbólico de significados sociais, sexuais, políticos, religiosos, éticos, estéticos etc" (CARNEIRO, 2003, p. 1).

\section{Metodologia}

Este estudo cruza análise de conteúdo (para apurar o que diz o programa Bem Estar em termos de alimentação) e observação participante em supermercado e academia de ginástica (para apurar como o público pensa a alimentação).

A análise de conteúdo foi aplicada ao programa Bem Estar, da Rede Globo. Foram analisados 81 programas (33,19\% dos exibidos em 2016). Escolheu-se o primeiro mês cheio de cada uma das quatro estações do ano. Neste trabalho, não se busca medir a quantidade de frases ou termos-chave, como prevê a análise de conteúdo quantitativa. Busca-se apenas destacar exemplos de frases, como orienta a análise de conteúdo qualitativa. "A análise de conteúdo é um conjunto de instrumentos metodológicos que se aplica a discursos extremamente diversificados. Ela absolve e cauciona o investigador pela atração pelo escondido, o latente, o não aparente" (BARDIN, 2010, p. 7).

A observação participante em supermercado e academia foi feita na Grande Florianópolis. Trata-se da região mais populosa de Santa Catarina, o Estado reconhecido pelos índices de qualidade de vida. No supermercado, a observação foi feita em visitas diárias, cada uma de 45 minutos, durante 90 dias, em 2016. Elas resultaram em 320 "situações" 
observadas (situações englobam diálogos entre pesquisador e pesquisado e diálogos entre pesquisados). O procedimento adotado foram conversas com clientes sobre alimentação. $\mathrm{Na}$ academia, a observação também foi feita durante três meses, em 2016. Foram 78 visitas, cada uma com duração entre 45 e 75 minutos. Elas resultaram em 250 "situações" observadas. Matriculado como aluno regular, o autor deste estudo treinou com outros alunos, de diferentes idades e classes sociais, procurando saber o que pensam sobre alimentação. A observação participante é uma técnica etnográfica. Consiste no contato direto do pesquisador com o fenômeno observado, para obter informações sobre a realidade dos atores sociais em seu próprio contexto. "A ideia é que, mediante sua presença, o pesquisador pode observar e registrar, de uma posição privilegiada, como as coisas são feitas, quem as realiza, como e onde" (RESTREPO, 2010, p. 12).

\section{O programa Bem Estar}

O programa Bem Estar é apresentado de segunda a sexta-feira, ao vivo, entre $10 \mathrm{~h}$ e $10 \mathrm{~h} 45$, com o argumento de "ajudar o público a levar uma vida mais saudável". O televisivo está na grade de produtos jornalísticos da emissora. É apresentado por dois jornalistas, que adotam a sobriedade do jornalismo ou a informalidade do entretenimento, de acordo com o tema em destaque. Eles contam com a participação de sete médicos consultores (pediatra, psiquiatra, ginecologista, dermatologista, oftalmologista, cardiologista e ortopedista), que participam ao vivo, em sistema de revezamento, de acordo com a pauta.

Além desses sete médicos, o programa escala outros profissionais da saúde, como fisioterapeutas, nutricionistas, farmacêuticos e outros médicos, para fazerem o papel de consultores. Entre titulares e convidados, ao menos dois especialistas participam a cada dia como "especialistas". Todos usam jalecos brancos com nome bordado e se tratam por "doutor". Os não médicos convidados a falar ao vivo, como pesquisadores de alimentos, também adotam o jaleco branco.

Em linhas gerais, a atração procura ensinar os segredos da alimentação saudável e a importância da atividade física. Costuma condenar a gordura e incentivar a magreza, apresentada como garantidora da boa saúde. 
O estúdio costuma imitar a sobriedade de um consultório médico, pintado em tom pastel e adornado com livros, maquetes médicas, tubos de ensaio e folhagens discretas. Mas pode reproduzir um ambiente de praia ou de piscina, com espreguiçadeira e guarda-sol, se o tema for ligado ao verão. $\mathrm{O}$ material usado na composição destes ambientes não costuma ser cenográfico. Assim, a mesa da cozinha tem frutas frescas e potes de castanhas, se o assunto exigir; e os consultores e apresentadores podem se servir. Aliás, é comum vê-los provando algum alimento saudável, como suco de couve ou um talo qualquer.

O surgimento do Bem Estar se deu após o sucesso de quadros sobre saúde lançados pela Rede Globo em outros programas jornalísticos da emissora. O mais notório deles foi a participação do médico Drauzio Varella no Fantástico. Em 2018, o Bem Estar atingia, segundo a emissora, 5,8 milhões de telespectadores por dia. A audiência era formada por $68 \%$ de mulheres e $32 \%$ de homens.

\section{O que diz o Bem Estar sobre a alimentação}

O programa Bem Estar costuma apresentar o alimento como algo que deve nutrir o corpo em vez de dar prazer: "Você pode acrescentar abóbora no molho para ele ficar mais nutritivo", diz nutricionista ao ensinar receita de molho (11/01, sobre macarrão).

Passa-se a ideia de que é no alimento que está o que o corpo precisa para ser saudável: "Tente atingir a meta de cálcio pela comida, e não por remédio", diz a apresentadora Michele Loretto (06/04, sobre saúde dos ossos).

Aquilo que ameaça o bom funcionamento do corpo é desencorajado: "Proteína em excesso pode formar pedras nos rins", diz mensagem na tela (28/01, sobre pedra nos rins); "Carboidrato: todo mundo hoje tem medo de comer", diz Michele Loretto ao comentar sobre alimentos que engordam (20/07, sobre tapioca).

O alimento que faz bem ao corpo é incentivado. "A dieta dos especialistas inclui muito peixe", diz reportagem sobre saúde da memória (08/07, sobre depressão infantil); "Cálcio é bom para os ossos, principalmente no leite", diz mensagem exibida na tela (06/05, sobre saúde 
nos ossos); "Mulheres devem comer ácido fólico para ter uma gestação segura" (21/07, sobre gravidez).

A eficiência do alimento está atrelada ao cálculo: tudo que é consumido pelo corpo deve ser calculado. Deve-se saber a quantidade de calorias, o percentual de gordura, a composição química: "Copo de iogurte tem 300 miligramas de cálcio; duas fatias de queijo equivalem a um copo de leite; 800 miligramas de cálcio é o que você precisa por dia", diz nutricionista (06/04, sobre saúde dos ossos).

O número ajuda na saúde: "Para fazer cocô, você precisa de 25 gramas de fibras por dia", diz mensagem exibida na tela (11/04, sobre prisão de ventre). Também está na meta do dia: "De 2 mil a 2,5 mil calorias é uma média boa para uma pessoa adulta", diz endocrinologista sobre o total de calorias por dia (04/07, sobre trabalho que engorda); "É óbvio que estas calorias [lanche da manhã] devem ser contadas na meta do dia: quantas calorias cabem no meu lanche da manhã, quantas calorias eu devo comer no lanche da tarde", diz nutricionista (04/07).

Saber a quantidade de calorias perdidas se converte naquilo a ser descoberto e festejado: “Quantas calorias você perdeu?", pergunta repórter a mulher que faz treino intervalado para emagrecer. " 560 ”, responde ela, com ar de satisfeita, após fazer 15 minutos de esteira, 15 minutos de ferro remando e 15 minutos de treino funcional. "Nossa, que bom", diz o repórter (18/10, sobre treino intervalar).

O programa Bem Estar enaltece a magreza ao ensinar a comer sem engordar ou a comer menos. "No próximo bloco vamos falar de um aliado da cozinha: o vinagre. Com ele dá para proteger os alimentos e ainda comer sem engordar", diz o apresentador Fernando Rocha (13/01, sobre conservantes); "O tomate ajuda a não engordar", diz Rocha (11/01, sobre macarrão); "Daqui a pouquinho a gente vai dar dica de ouro para você comer sem engordar", diz Rocha (04/07, sobre trabalho que engorda). "Sabia que comer casca de fruta ajuda a controlar o colesterol? É a nossa dica de hoje no quadro comer sem engordar", diz a apresentadora Michele Loretto (21/04, sobre colesterol).

A magreza é festejada como sinônimo de beleza ou como boa notícia. "Até porque, se ela malha [telespectadora], é porque quer ficar bem [bonita] e não quer engordar", diz a apresentadora Mariana Ferrão (18/01, sobre comer à noite); "A boa notícia é que você está mais magro", diz 
nutricionista ao apresentador Fernando Rocha, após ele se pesar em programa de emagrecimento (25/07, sobre IMC).

Busca-se espantar a gordura: "Prefira milho sem manteiga porque a gente não quer gordura”, diz pediatra (21/01, sobre comida de praia); "Bacon? Socorro", exclama médico sobre alimentos que causam colesterol (26/01, sobre colesterol); "Olha só que coisa abençoada: além de ficar mais gostoso, quando você coloca o queijo, diminui o índice glicêmico", diz Fernando Rocha ao botar queijo no pão (carboidrato puro eleva o pico glicêmico) (19/04, sobre doces); "Você gosta de picolé", pergunta Fernando. "Adoro. Sem engordar, melhor ainda", responde Mariana (05/01, sobre água de coco); "Você vai ajudar quatro gordinhos. Você vai ajudar que eles não tenham mais este título", diz Fernando Rocha, ao pedir votos aos candidatos do reality de emagrecimento (29/04, sobre emagrecimento).

O programa valoriza o corpo mediano. "A gente pegou assim uma média de um peso feminino. Temos aqui uma mulher elegante, esbelta, que pesa $68 \mathrm{~kg}$. Ela vai precisar de 68 gramas de proteína”, diz Fernando Rocha. "Vamos pegar o modelo masculino: um rapaz saudável de 90 kg", diz o apresentador (01/07, sobre lanches).

$\mathrm{O}$ gordo pode ser visto como alguém anormal: "O obeso ganha menos que uma pessoa normal [o gordo não é normal?]”, diz médico (04/07, sobre trabalho que engorda); "Pessoa normal", diz texto de infográfico sobre hormônios; "Obeso" é como o mesmo infográfico se refere às demais pessoas (18/07, sobre tratamento para emagrecer) [ou seja, $o$ mundo, para o programa, é dividido entre normais e obesos].

No programa, o nutricionista, especialista em alimentos, aparece como aquele que detém o conhecimento sobre a alimentação, sabendo tirar o máximo proveito dos alimentos: "A cenoura é antioxidante e anti-inflamatória. É bom para o coração", diz nutricionista ao ensinar a fazer "macarrão de mentira" por trocar massa de farinha por tiras de abobrinha (11/01, sobre macarrão); “Tomate previne câncer” (11/01).

O nutricionista surge como aquele que ajuda: "Para fazer aquele cocô de dar orgulho na gente, aquele que a gente fica feliz, anota aí uma misturinha que ajuda: aveia, água e fruta" (11/04, sobre prisão de ventre); "Alimentos com triptofano (aveia, batata doce e feijão) ajudam a dormir melhor" (18/01, sobre comer à noite).

Ao apresentar-se como autoridade em alimentos, o nutricionista ganha 
autoridade e passa a dizer o que está certo ou errado e o que pode ou não pode na hora de comer. "Está certíssimo", diz nutricionista à telespectadora que mandou foto de prato de macarrão com azeite e castanha (11/01, sobre macarrão).

Autorizado a opinar, o profissional da nutrição passa a regular o prato alheio. "Se você tiver um pudim de leite condensado você vai abrir e fechar a geladeira até ele acabar. Coloque frutas picadas na frente", diz nutricionista ao ensinar a organizar a geladeira para "não cair em tentação" (04/07, sobre trabalho que engorda).

\section{A alimentação no cotidiano do público}

A observação participante com clientes de supermercado e alunos de academia mostra que, em boa parte dos casos, a escolha da comida não obedece mais, em primeiro lugar, ao prazer; o alimento é frequentemente escolhido pelo potencial que tem de nutrir o corpo. Há, portanto, uma compatibilidade com o discurso da TV sobre alimentos.

Nas conversas sobre comida com o público pesquisado, nota-se que o aspecto saudável guia as escolhas de compra: "Não é como aquele pão quentinho de padaria, mas faz bem. E se faz bem, a gente compra", diz mulher, cliente de supermercado, ao autor deste estudo quando questionada se gostava de pão integral; "Prefiro a Coca-Cola normal. Mas se a gente não pode mais tomar, levo a zero açúcar mesmo. O gosto não é o mesmo, nem se compara, mas é mais saudável", diz mulher adulta, cliente de supermercado, que levava na cestinha outros produtos diet.

Entre os observados é comum encontrar pessoas dispostas a abrir mão do sabor em nome da saúde: "A gente compra este queijo [branco] porque é mais saudável. Mas não tem gosto de nada. O sem sal não tem gosto nenhum", diz mulher que compra queijo da marca Holandês; "Eu levo o Minas. Ele é mais saudável. Tem até um gostinho de queijo. Tem muito queijo por aí que nem parece queijo", diz mulher madura que observava a conversa na gôndola de frios; "Acho que o café fica com gosto de rapadura. É estranho. Mas todo mundo diz que o mascavo é mais saudável, então eu estou levando", diz mulher sobre o açúcar de cor escura que inseriu na dieta da família.

O alimento eficiente pode ser menos saboroso, mas costuma ser mais 
funcional. E esta é uma característica muito valorizada entre os pesquisados. Nota-se que a evacuação regular, além de indicar que o organismo está funcionando bem, é uma forma de eliminar peso e se aproximar do ideal do corpo magro: "Ele demora mais para cozinhar, mas vale a pena porque melhora bem a tua digestão", diz mulher jovem, apontando discretamente em direção ao intestino; "Não, moço. Este não tem fruta. Não tem nem gosto. Mas é bom para regular o intestino", diz mulher adulta, que traz saco plástico de casa para encher de iogurte, ao autor deste estudo.

O alimento eficiente busca o bom funcionamento do corpo: "A gente não gosta muito de chocolate. Mas é uma gordura boa. Ajuda a aumentar o colesterol bom", diz casal que acabara de comprar oito barras de chocolate 70\% cacau; "Sempre achei que comer capim é coisa de boi. Mas dizem que desentope as veias, aí a gente leva", diz homem de meia idade, em tom de brincadeira, sobre o alface; "Acho muito doce, meio enjoado. Mas faz bem para o coração", diz homem adulto sobre o suco de uva natural.

O eficiente pode ser o produto ou a forma de preparar o produto: “Tudo que tu fizer grelhado será mais saudável. O frango grelhado é ótimo. Mas é melhor grelhar a coxa sem osso. Ela é mais magrinha, mais saudável", diz homem que aproveitava a promoção de frango no supermercado; "Batata doce faz bem de qualquer jeito. Mas se tu fizeres no forno, assadinha, faz mais bem ainda", diz mulher adulta, aluna de academia; "Eu tiro a pele e cozinho o frango. Ele fica mais magrinho, sem gordura nenhuma”, diz mulher, cliente de supermercado.

A observação mostra que, na era do corpo esguio, elogiar é chamar o outro de magro: "Como tu estás bem, estás magra", diz jovem ao reencontrar amiga no supermercado. "Ah, obrigado. Tu também estás magra”, responde a amiga, retribuindo a gentileza; "Tu já destes uma afinada, não é? Estás bem. Bom te ver assim. Segue firme”, diz homem a colega de academia; "Nossa, como ele está fininho, não é?" diz mulher, adulta e magra, sobre o marido da amiga, ao vê-lo no supermercado.

Não há idade para ser magro. "Vamos parar de comer macarrão, rapazinho? Tu queres ficar como aquelas crianças gordas lá da escola?", diz homem adulto ao filho na praça de alimentação do supermercado; "Meu neto está uma pena. Está gordinho. A gente já está até pensando em fazer um tratamento nele", diz mulher, à amiga da academia, em 
conversa sobre obesidade infantil.

O trabalho de campo mostra que a norma alimentar, que determina o que é certo ou errado sobre alimentação, regula quantidades e priva do prazer para preservar a magreza: "Nossa, mas tu vai comer três de cada vez", pergunta mãe à menina que, no sábado à noite, comprava barras de cereal para levar de lanche à escola; "Um pode. Dois, nem pensar", diz mulher à filha que queria comprar pacote de bolacha recheada; "Está bem, vamos levar. Mas escolhe o sem pintura", diz homem, jovem, à esposa. Ela queria comprar doce de natal para o café da tarde.

A norma alimentar às vezes prevê a vigilância. "Eu estou de olho: ficas comprando iogurte saudável para depois ir lá e se empapuçar de torta alemã”, diz jovem magro à namorada que comprava iogurte Vigor Grego, que promete saciar a fome com poucas calorias; "Se a gente não ficar em cima, ele come mais do que deve", diz mulher, aluna de academia, sobre o marido; "Eu também fico em cima. Se deixar, ele come um boi inteiro", responde a amiga.

A observação indica que, em alguns momentos, a norma alimentar cria sensação de culpa. Para ficar com a consciência tranquila, faz-se compensações: "Já que a gente está levando bolo recheado, escolhe o refrigerante diet", diz homem à esposa; "Se tu queres levar, a gente leva. Mas depois tem que pegar pesado na esteira", diz jovem ao namorado que queria comprar pão de queijo; “Tá bom, pode levar”, concorda a mulher com o marido que quis comprar torresmo, um produto proibido no ambiente saudável. Na cesta do casal tinha suco de laranja integral, torrada, pão integral e granola.

A observação mostra que o nutricionista, que frequentemente aparece nos programas de televisão vestindo jaleco branco, pode ser confundido com um médico: "Eu achava que nutricionista era o mesmo que médico", diz mulher, madura, que comprava pasta de amendoim para passar no pão. "Foi a nutricionista que me mandou comer isso", diz ela sobre o doce que promete alimentar com baixo índice calórico e alto índice de gordura boa; "Eu nunca tinha ido no nutricionista. Fui depois do infarto. Gostei. Estou comendo o que ela mandou e já me sinto bem melhor", diz cliente de supermercado, cardíaca e levemente obesa, que reformou a dieta da família após a consulta; "No começo eu estranhei um pouco. Era muita coisa que não podia comer. Mas com a tempo a gente se acostuma", diz homem maduro que frequenta academia e deci- 
diu equilibrar atividade física e alimentação saudável; "Uma amiga foi [à nutricionista] e me indicou. Fui e gostei também. Mas ela é bem pingo no i. Tem que fazer tudo bem direitinho", diz cliente de supermercado, maduro e diabético.

Apresentado na televisão como aquele que conhece os segredos da alimentação saudável, que sabe extrair o máximo de eficiência dos alimentos e que pode nos ajudar a atingir ou a manter a saúde, o nutricionista passa a dizer o que pode e o que não pode: "A gente quer, mas não pode", diz jovem aluna de academia à amiga que ofereceu pão de queijo na saída do treino. "Minha nutricionista não me deixa comer queijo amarelo", justifica; "A cara está ótima. Mas leva farinha branca, e eu estou cortando farinha branca. Minha nutricionista disse que farinha branca entope a gente", diz mulher adulta e magra à atendente da padaria do supermercado que lhe ofereceu sonho de leite Ninho.

O que é dito pelo nutricionista interfere em grandes decisões, como adotar uma dieta para perder até $40 \%$ do peso, ou pequenas escolhas do dia a dia, como a compra de adoçante. "Minha nutricionista diz que este é o melhor que tem", diz mulher de pele bem cuidada sobre produto à base de sacarose que custa $\mathrm{R} \$ 17$, seis vezes mais que o adoçante comum.

\section{Considerações finais}

A análise de conteúdo mostra que a alimentação foi o tema mais trabalhado pelo Bem Estar no período pesquisado: dos 81 programas estudados, 25 (30,86\%) trataram especificamente sobre alimentação. Os demais abordaram temas como doença (23 programas), comportamento (11), estética (7), males urbanos (6), segredos do corpo (5) e atividade física (4).

Considerando só as reportagens exibidas no programa, a alimentação também foi o tema mais trabalhado: na amostra analisada, foram veiculadas 240 reportagens; desse total, 98 (40,83\%) tratavam de temas ligados à alimentação; as demais referiram-se a rubricas como doença, cuidados estéticos, males urbanos e comportamento.

A observação participante mostrou que o cotidiano de clientes de supermercado e alunos de academia contempla elementos do discurso midiático sobre alimentação. Ou seja, entre os pesquisados percebeu-se 
quem adota o discurso da mídia e incorpora em seu dia a dia hábitos alimentares apresentados na TV como saudáveis. Nesse sentido, esse trabalho casa com os estudos clássicos, iniciados por Harold Lasswell em 1918, que mostram que os meios de comunicação exercem alguma influência em sua audiência.

Como visto na breve revisão bibliográfica sobre alimentação, a preocupação com a alimentação não começa em nossos dias, a reboque de programas de televisão sobre saúde e bem-estar. Mas não se pode negar que atualmente há uma atenção midiática sem igual em torno deste tema, o que reflete na população.

No discurso midiático, tomando como exemplo o programa Bem Estar, o tema alimentação é frequentemente associado à saúde. E saúde, por sua vez, é o termo mais associado à vida. Nota-se, aí, um elo entre alimentação e biopoder. O biopoder, como visto na introdução, é uma técnica de poder que junta disciplina (ações que incidem sobre os corpos dos indivíduos) e biopolítica (ações que buscam regular a população como um todo). O objetivo do biopoder é produzir corpos economicamente ativos e politicamente dóceis.

Na obra de Foucault (2012), escolhida como base deste trabalho, o biopoder se vale do sexo para aplicar, na sociedade, de maneira conjunta, ações de disciplina e biopolítica. Isso ocorre porque o sexo é um dado natural (de cada indivíduo) e universal (típico na nossa espécie). A pergunta que surge é: a alimentação, também sendo natural e universal, não estaria em condições de servir de ponto de apoio para intervenção do biopoder?

Para este trabalho a resposta é sim. A alimentação, como o sexo, dá acesso ao corpo. Ela é fonte de atenção permanente, desperta interesse e, comparando com o sexo, é um tema mais fácil de ser abordado na TV (não há pudores, restrição de horário e público).

No resgate histórico sobre o sexo feito por Foucault (2012), o sexo como fim em si mesmo (fazer sexo só para ter prazer) foi desencorajado em muitas épocas porque isso tirava dos indivíduos a energia que deveriam colocar no trabalho. Na alimentação, como foi possível observar no discurso midiático e no cotidiano do público, o prazer (comer o que se gosta, e não o que nutre o corpo) também vem sendo desencorajado. Seria porque o prazer à mesa leva ao risco de um corpo gordo ou doente, incompatível com o mercado de trabalho? 


\section{REFERÊNCIAS}

BARDIN, L. 2010. Análise de conteúdo. Lisboa: Edições 70

BROTHWELL, D.; BROTHWELL, P. 1971. A alimentação na Antiguidade. Lisboa: Gris impressores

CARNEIRO, H. 2003. Comida e sociedade: uma história da alimentação. Rio de Janeiro: Elsevier

DEFLEUR, Melvin. BALL-ROKEACH, Sandra. Teorias da Comunicação de massa; tradução de Otávio Alves Velho. Rio de Janeiro: Jorge Zahar Editor, 1993

FISCHLER, C. 1995. El (h) omnívoro: el gusto, la cocina y el cuerpo; tradução de Mario Merlino. Barcelona: Anagrama

FOUCAULT, M. 2012. História da sexualidade I: a vontade de saber; tradução de

GELIS, J. 2008. O corpo, a igreja e o sagrado. In: CORBIN, Alain; COUR

TINE, Jean-Jacques; VIGARELLO, Georges. História do corpo: do Renascimento às luzes. Petrópolis: Vozes

LE GOFF, J.; TRUONG, N. 2006. Uma história do corpo na Idade Média; tradução de Marcos Flamino Peres. Rio de Janeiro: Civilização Brasileira, 2006

ORNELLAS, L. 2000. A alimentação através dos tempos. Florianópolis: Editora da UFSC

POULAIN, J.P. 2013. Sociologias da alimentação: os comedores e o espaço social alimentar. 2. ed; tradução de Rossana Pacheco da Costa Proença, Carmen Sílvia Rial e Jaimir Conte. Florianópolis: Editora UFSC

RESTREPO, E. 2010. Técnicas etnográficas. In: Especialización en Métodos y Técnicas de Investigación en Ciencias Sociales. Fucla 